\title{
$\mathrm{EA}$ 성과평가 모델의 설계 및 적용사례에 관한 연구 \\ 이 석 균 ${ }^{\dagger} \cdot$ 이 영 민 ${ }^{\dagger+} \cdot$ 류 성 열 $^{+\dagger}$
}

요 약

현재 정부 각 부처는 「정보시스템의 효율적 도입 및 운영 등에 관한 법률」에 의해 $\mathrm{EA}$ 를 도입하여 운용하고 있으나 이의 평가 체계 및 지 표는 제대로 갖춰져 있지 않다. 특히 $\mathrm{EA}$ 의 성과평가를 위한 모델이 없을 뿐만 아니라 측정 할 수 있는 방법도 미흡하다.

본 연구에서는 $\mathrm{EA}$ 성과평가를 위해 국내 범정부 성과참조모델과 미 연방 성과참조모델을 기반으로 8개의 평가 영역 및 17 개의 평가지표를 도출하였다. 또한, 미 $\mathrm{OMB}$ 및 국내 범정부 $\mathrm{EA}$ 성숙도 모델을 기반으로 8 개의 평가 영역 및 10 개의 평가지표를 도출하여, 이를 기반으로 $\mathrm{EA}$ 성과평가를 위한 업무, 고객, 프로세스, 인적자본 및 기술의 5개 영역으로 구성된 성과평가 모델을 제안하였다.

제안한 모델의 검증을 위해 3 개 기관에 적용하여 각 기관의 $\mathrm{EA}$ 성과를 평가하였고, 평가 결과를 검증하기 위해 범정부 $\mathrm{EA}$ 성숙도 모델의 성과평가 영역과도 비교 평가하였다. 또한, 제안한 성과평가모델의 측정지표를 기존의 $\mathrm{EA}$ 성숙도 모델 및 성과참조모델과도 비교 분석하였다. 이러한 비교 분석 결과를 바탕으로 제안한 성과평가모델을 검증하였다.

키워드 : $\mathrm{EA} / \mathrm{ITA}$, 성과평가, 아키텍처

\section{A Study on the Design of EA Performance Evaluation Model and the Application Case}

\author{
Seok-Kyun Lee $\cdot$ Young-Min Lee ${ }^{++} \cdot$ Sung-Yul Rhew ${ }^{+++}$
}

\begin{abstract}
Korean government has operated EA by the act on efficient introduction of information system and operation, etc. But the evaluation system for EA and the criteria don't prepare well. Particularly, There is no model for EA performance measurement and the way is insufficient. In this study, we derived 8 areas and 17 criteria for the performance evaluation based on the Performance Reference Model of U.S FEA and Korea. And we also derived 8 areas and 10 criteria for it based on the OMB EA Assessment Framework and the EA maturity model in Korea. We propose the performance evaluation model of the five areas that consists of the business performance, customer performance, process, human resource and the technology for EA performance evaluation.

To verify the model, we applied the model to three organizations and evaluated EA performance. In addition, we compared the performance result with the performance evaluation area of EA maturity model of Korea to verify the result. We also analyzed the criteria of the proposed performance evaluation model with the current EA maturity model and Performance Reference Model of Korea. As a result of the evaluation, we verified of the proposed performance evaluation model, too.
\end{abstract}

Keywords : EA/ITA, Performance Measurement, Architecture

\section{1. 서 론}

근래 정부의 정보화사업 추진은 행정업무의 혁신 및 효율 성 제고를 통한 대국민서비스 제고와 다부처 연계사업의 증 가 등으로 그 규모와 복잡성이 더욱 커지고 있다. 이는 정

\footnotetext{
※ 본 연구는 숭실대학교 교내연구비의 지원으로 이루어졌음.

† 준 회 원 : 숭실대학교 컴퓨터학과 박사과정 수료

†† 준 회 원 : 숭실대학교 컴퓨터학과 박사과정

왜 종신회원: 숭실대학교 컴퓨터학과 교수

논문접수 : 2009년 2월 25일

수 정 일 : 1 차 2009년 3월 16 일, 2 차 2009년 4월 2일

심사완료 : 2009년 4월 2일
}

부의 정보화예산이 최근 5년간('04 '08년) 연평균 4.5\%로 큰 증가율을 보이고 있는 것을 보아도 알 수 있다. 그러나 '공공부문 정보자원실태조사결과 보고서'(2002.4)에 따르면 “정보기술자원관리의 효율성이 낮고 체계적이지 못하다”고 지적하였듯이 그 관리적인 측면에서는 중복투자와 비효율적 운영 등의 문제점을 안고 있다. 이러한 문제점을 개선하고 자 정부는 2006년 7월1일부터 '정보시스템의 효율적 도입 및 운영 등에 관한 법률'을 제정하여 시행하기에 이르렀다. 이 를 기반으로 각 부처는 $\mathrm{EA}$ 를 경쟁적으로 도입하여 운영하 고 있는 실정이다. 
$\mathrm{EA}$ 의 도입 및 운영을 통해 효율적인 정보자원의 관리 및 상호운용성 확보, 정보화 투자 기준 마련 등 체계적인 정보 자원 관리체계의 수립을 도모할 수 있게 되었으나 $\mathrm{EA}$ 의 성 과가 어느 정도인가를 평가할 수 있는 성과평가 방법은 전 무한 상태이다. 따라서 EA성과평가 모델이 없는 것은 물론 성과측정 방법 역시도 미흡한 실정이다. 그나마 다행인 것 은 기관의 $\mathrm{EA}$ 성숙도 수준을 측정할 수 있는 성숙도 모델 은 그나마 있다는 것이다. 그러나 이는 조직의 $\mathrm{EA}$ 성숙 수 준 전반을 평가하는 것이지 성과에 특화되어 있지는 않다. 물론, 정보화사업에 대한 성과평가를 위한 모델과 방법은 있으나 이는 일반적인 재정사업의 성과평가를 위한 내용이 정보화사업 평가에 좀더 특화된 것이지 당초 $\mathrm{EA}$ 평가를 위 한 것은 아니다.

따라서 본 연구에서는 국내 - 외의 EA성숙도와 국내 정보 화사업 성과평가에 대한 연구를 수행하고 이를 기반으로 손 쉽게 $\mathrm{EA}$ 성과를 평가할 수 있도록 $\mathrm{EA}$ 성과평가 모델을 설계 하여 제안하고자 한다.

본 논문은 관련 성과모델 연구와 평가모델의 설계, 적용 사례를 통한 검증으로 구성하였다.

\section{2. 관련 연구}

$\mathrm{EA}$ 의 특징과 성숙도 모델, 조직의 성과평가 및 정보화 성과평가에 관한 연구를 통해 $\mathrm{EA}$ 에 대한 성과평가 모델을 설계하고자 국 - 내외 관련 문헌조사와 논문 등을 연구 - 분 석하였다.

\subsection{EA(Enterprise Architecture)}

$\mathrm{EA}$ 는 조직의 비전 및 목적의 달성을 위해 전사적인 IT 기본전략 및 계획을 수립하고 기술역량과 비즈니스 요구 증 진을 위한 정보관리의 최적화 및 IT전략과 업무 기능의 정 비를 통한 정보화투자의 중복방지, 업무프로세스의 개선 및 비용 절감을 위한 기반 구조와 어플리케이션의 공유를 증진 시킨다. 1987년 Zachman[1]은 “정보시스템의 발전에 따라 전사적 아키텍처는 선택사항이 아닌 필수사항이 되어간다” 라고 말하였다. [1-4]에서 말하는 $\mathrm{EA}$ 를 구축해야하는 이유 와 목적을 살펴보면 $\mathrm{EA}$ 의 궁극적인 목적은 기업의 목적을 달성하기 위한 정렬된 조직의 모습이라고 할 수 있음으로

〈표 1〉EA 목적을 반영한 평가 지표

\begin{tabular}{|c|c|c|}
\hline \multicolumn{3}{|c|}{ 평가 지표 } \\
\hline \hline 업무 활용성 & 업무 효율성 & 인원 효율성 \\
\hline 자원 활용성 & 자원 효율성 & 자원 중복성 \\
\hline 자원 공유성 & 고객 만족도 & 평가방법구비성 \\
\hline 지속적 평가 & 의사결정 신속성 & 표준 준수성 \\
\hline 접근 편의성 & 투자 적합성 & 시스템 중복성 \\
\hline 시스템 확장 편의성 & 시스템 수정 편의성 & \\
\hline
\end{tabular}

조직의 목적을 달성하기 위하여 EA가 지원하는 것(Business, Staff, Resource, Customer need 등)이 지표가 된다. 결과적 으로 $\mathrm{EA}$ 성과평가는 조직 목적을 달성하기 위해 $\mathrm{EA}$ 가 기 여한 정도에 대한 평가라고 볼 수 있다. 그러므로 $\mathrm{EA}$ 를 통 한 이득(조직 목적을 지원하는 영역)이 $\mathrm{EA}$ 성과평가 모델 에 반영되어야 한다. <표 $1>$ 은 본 논문에서 $\mathrm{EA}$ 의 성과평가 시 반영할 평가 지표를 정리한 것이다.

\subsection{EA 성숙도 모델}

$\mathrm{EA}$ 성숙도 모델은 $\mathrm{EA}$ 성숙도 평가 목적에 따라 $\mathrm{EA}$ 의 각 영역을 평가한다. 연구 분석을 통해 도출된 평가영역 및 장단점은 향후 $\mathrm{EA}$ 성과평가 모델을 마련하는 근거 자료로 서 활용한다.

\subsection{1 $\mathrm{OMB}$ 의 $\mathrm{EAAF}$}

$\mathrm{EAAF}$ 는 미국 관리예산처(OMB, Office of Management and Budget)에서 연구된 모델[5]로 $\mathrm{EA}$ 성숙도를 평가하여 지 속적인 개선 방향을 제시하기 위한 성숙도 모델이다. $\mathrm{EAAF}$ (Enterprise Architecture Assessment Framework)는 완성 도, 활용, 결과의 3 개 능력 및 14 개 평가 요소를 기반으로 하여 각 능력별로 다섯 단계의 성숙도에 따라 평가를 수행 한다. 또한 연간 매 분기별 평가와 보고를 통해 성과의 개 선여부를 모니터링 한다.

\subsection{2 행정자치부의 EA 성숙도모델}

정부의 정보자원관리 프로세스 프레임워크 $(\mathrm{G}-\mathrm{IRMPF}$, Government Information Resource Management Process Framework)의 구성요소로써 정보자원관리의 성숙도 평가를 통하여 효과적인 수행을 위한 지침서[6]이다. G-IRMPF의 9 개 영역, 36 개 프로세스를 기준으로 성숙도 모델이 정립되 었으며 다섯 단계의 성숙도에 따라 관리구조와 관리시스템 의 프로세스, 도구, 역량, 책임과 역할을 대상으로 하여 평가 를 수행한다.

\section{2 .3 정보통신부의 $\mathrm{EA}$ 성숙도모델}

공공 기관의 $\mathrm{EA}$ 성숙도 수준을 판단하고 개선방향을 제시 하기 위해 정통부에서 마련한 성숙도 모델[7]이다. 성숙도 평가는 평가도구를 활용하고 그 대상을 공공기관으로 하여 $\mathrm{EA}$ 프로젝트 수행이 활발하게 이루어지는 범위에서 평가가 이루어진다. 성숙도 모델은 수립, 활용, 관리의 세 가지 역량 및 16 개 평가 항목을 기반으로 하여 각 역량의 산술 평균을 구해 성숙도를 평가한다.

\section{3 범정부 PRM}

$\mathrm{EA}$ 의 성과 평가를 위한 참조 모델로는 범정부 $\mathrm{PRM}(\mathrm{Per}-$ formance Reference Model: 성과참조모델)[8]이 있다. PRM 은 조직에서 수행하는 정보화사업 및 기타 IT관련 투자사업 의 일관된 성과평가 및 관리를 지원하고 해당 사업이 조직 의 업무기능 성과와 정책목표 달성을 지원하는 표준화된 성 
과관리 체계를 위한 모델이다. $\mathrm{PRM}$ 은 범정부 $\mathrm{EA}$ 의 추진을 위한 5개 참조모델 중 정보화사업의 성과를 평가하기위해 평가요소를 체계적으로 정리한 것으로 최상위 수준에서 업 무기능, 고객성과, 프로세스, 기술 영역으로 구분된다.

$\mathrm{PRM}$ 의 장점으로는 성과평가 및 관리의 일관성, 업무와 성과간의 정렬, 가시경로의 조망과 같은 투입 성과요소와 결과 성과요소를 가시경로를 통해 설계하여 조망한다. 또한 평가지표의 노하우를 축적하여 향후 타 정보화사업의 평가 에 응용하고 활용하여 비용을 절감할 수 있으며 평가 지표 를 성과계획, 성과 모니터링, 성과평가 등 성과관리를 위한 다양한 도구로 활용할 수 있다.

그러나 범정부 $\mathrm{PRM}$ 은 $\mathrm{EA}$ 의 성과평가를 위한 참조모델 로써의 역할이지 $\mathrm{PRM}$ 을 그대로 성과평가모델로 사용하기 에는 그 평가요소가 각 조직의 특성에 적절하지 않을 수 있 다. PRM은 $\mathrm{EA}$ 의 추진을 위한 결과 및 성과를 평가하는 모 델로는 평가요소가 부족하기 때문에 조직 특성에 맞는 성과 평가 모델의 개발이 필요하다.

\section{4 조직의 성과평가 및 정보화 성과평가 모델}

$\mathrm{EA}$ 의 성과평가 방향 정립을 위해 조직의 성과평가 및 정 보화 성과평가 모델 등을 조사- 분석하였다. 그러나 이러한 연구들은 실제 $\mathrm{EA}$ 의 범위보다 좀 더 넓은 범위를 차지하고 있으므로 $\mathrm{EA}$ 성과평가에 직접 적용할 수 없다는 단점이 있 다. 하지만 $\mathrm{EA}$ 의 성과평가를 위한 방향을 제시한다는 점에 서는 그 의미가 있다.

\subsubsection{IT 솔루션의 성과평가}

기업의 성과평가 모델은 기업의 자금부족, 전문 인력 부 족, 정보화 효과에 대한 인식부족 등으로 정보화 추진상의 어려움을 해결하고자 개발된 IT 솔루션의 도입에 대한 성과 평가 방법론으로써 매출증대, 비용절감 등 정보화 투자 효 과를 정량적으로 분석하여 IT 솔루션 도입의 성과평가 및 효과를 검증하고, 업무 및 솔루션 개선방안을 도출하고자 하는 평가방법이다. 따라서 이러한 IT 솔루션 도입의 성과 를 평가하기 위한 방법론 프레임워크가 제시되어 있는데 여 기에는 환경 분석, 정보화 영향도 분석, 정보화 성과지표 정 의, 정보화 성과평가, 종합 성과분석 등의 총 5 가지로 단계 별 활동과 이에 대한 세부 작업(Task)을 정의하고 있다.

그러나 IT 솔루션 도입의 성과평가로서의 정보화 기여도 와 성과평가의 세부 활동 및 지표는 $\mathrm{EA}$ 성과평가 항목의 평 가요소로써는 적용이 가능하지만 $\mathrm{EA}$ 성과를 평가하는 것이 아니라 솔루션 도입에 따른 성과평가라는 점에서 $\mathrm{EA}$ 성과 평가에 맞는 평가요소를 추출할 필요가 있다.

\section{4 .2 정보화 성과평가 모델}

정보화 투자에 대한 성과평가는 1970년대 조직의 업무, 인간과 시스템간의 접속 위주의 평가에서 1980년대에는 정보 기술의 급격한 성장에 따라 평가방법에 대한 다양한 연구가 이루어졌다. 이러한 연구는 정보화의 적정 투자규모 제시,
정보화 효과의 평가 및 계량화, 정보화의 수익성 분석 등 크게 3 가지로 분류할 수 있다. 정보화 성과평가 모델로는 대 표적으로 IS Success(Information System Success: 정보시스 템 성공) 모델[9], BSC (Balanced Score Card : 일목균형요약 표) 모델[10], 3-Motion (Automation, Information, Transformation) 모델[11], 전자정부의 효율성 측정을 위한 정보화 성과평가 모델[12], Value Chain(가치사슬) 모델 등이 있다.

이러한 정보화 성과평가 모델들의 관점과 평가 요소는 $\mathrm{EA}$ 성과측정 항목의 평가요소로써의 적용이 가능하다. 각 모델들은 성과를 평가하는 대상 및 방법은 다르지만 $\mathrm{EA}$ 의 성과평가를 위한 요소로써 적용이 가능하여 이를 본 연구에 서는 일부 활용하였다.

\subsection{6시그마에서의 성과평가}

6 시그마[13]는 경영의 모든 부분에서 발생하는 결함의 원 인을 통계적으로 측정, 분석하고 그 원인을 제거하는 체계 적인 혁신 활동이다. 6 시그마는 고객 관점에서 품질에 영향 을 미치는 CTQ (Critical to Quality: 핵심요소)를 찾아 개선 하는데 초점을 둔다. 각 업종별 금융업, IT산업, 의료, 유통, 레저, 보안, 공공 부문 등 서비스업 전반에서 6시그마가 널 리 활용되고 있다. 6시그마를 기반으로 많은 방법론들이 존재 하나 대표적으로 DMAIC(Define, Measure, Analyze, Improve, Control) [14], DMADOV(Define, Measure, Analyze, Design, Optimize, Verify)[15] 방법이 존재한다.

6 시그마는 경영 및 조직의 성과 부분에 큰 영향을 주었던 개념이며 많은 방법론이 개발되었으나 이는 조직과 경영을 대상으로 하고 있고 $\mathrm{EA}$ 를 대상으로 하고 있진 않다. 본 연 구에서는 6시그마의 절차와 방법 및 지표들을 참고하였다.

\section{3. $\mathrm{EA}$ 성과평가 모델의 설계}

본 장에서는 $\mathrm{EA}$ 성과평가 모델을 수립하기 위해서 성과 평가 모델의 기반이 되는 범정부 PRM 및 미 연방 PRM과 $\mathrm{EA}$ 성숙도 모델의 각 요소 중 성과와 관련된 평가지표를 도출하여 평가모델을 제시하고자 한다.

성과평가 모델을 수립하기 위해 $\mathrm{EA}$ 의 목표와 원칙을 기 반으로 (그림 1)과 같이 5 개의 평가 영역과 13 개의 평가항 목을 도출하였다. 2.2절에서 설명한 기존 $\mathrm{EA}$ 성숙도 모델의 평가영역 및 평가지표 그리고<표 $1>$ 과 같이 $\mathrm{EA}$ 목적을 기반으로 도출한 지표를 종합하였다. 이 지표들과 $\mathrm{PRM}$ 의 평가 지표를 종합하여 중복된 지표와 요소를 제거하고 각 영역에 맞는 지표를 재정립하였다.

평가 영역별 분류체계는 도출한 지표와 영역을 $\mathrm{PRM}$ 의 평가영역과 평가항목에 따라 재정립하였으며, 각 평가영역 과 평가항목에 반영되지 못한 일부 평가지표는 $\mathrm{PRM}$ 에 평 가영역과 항목을 추가(인적 자본 영역, 인적자원 항목, 교육 훈련 항목)하여 반영하였다. 표준 가시 경로의 경우, 도출한 분류체계를 기반으로 각 하위 지표에 대해 조사하고 이를 품질 지표, 이용 지표, 효과 지표로 분류하여 지표별 가시 
경로를 산출하였으며 각 평가지표에 대한 평가방법을 효율 적으로 표현할 수 있는 질문을 도출하여 평가결과를 선택할 수 있도록 작성하였다. (그림 1)은 성과 평과영역과 평가지 표의 도출 과정을 그림으로 표현한 것이다.
$3.1 \mathrm{EA}$ 성과평가모델 프레임워크

범정부 $\mathrm{PRM}$ 과 기업의 성과평가 모델 및 범정부 $\mathrm{EA}$ 성숙 도 모델을 활용한 성과 평가의 기본 요소를 체계화한 “성과 평가 모델 프레임워크”는 (그림 2)와 같이 영역별 분류 체

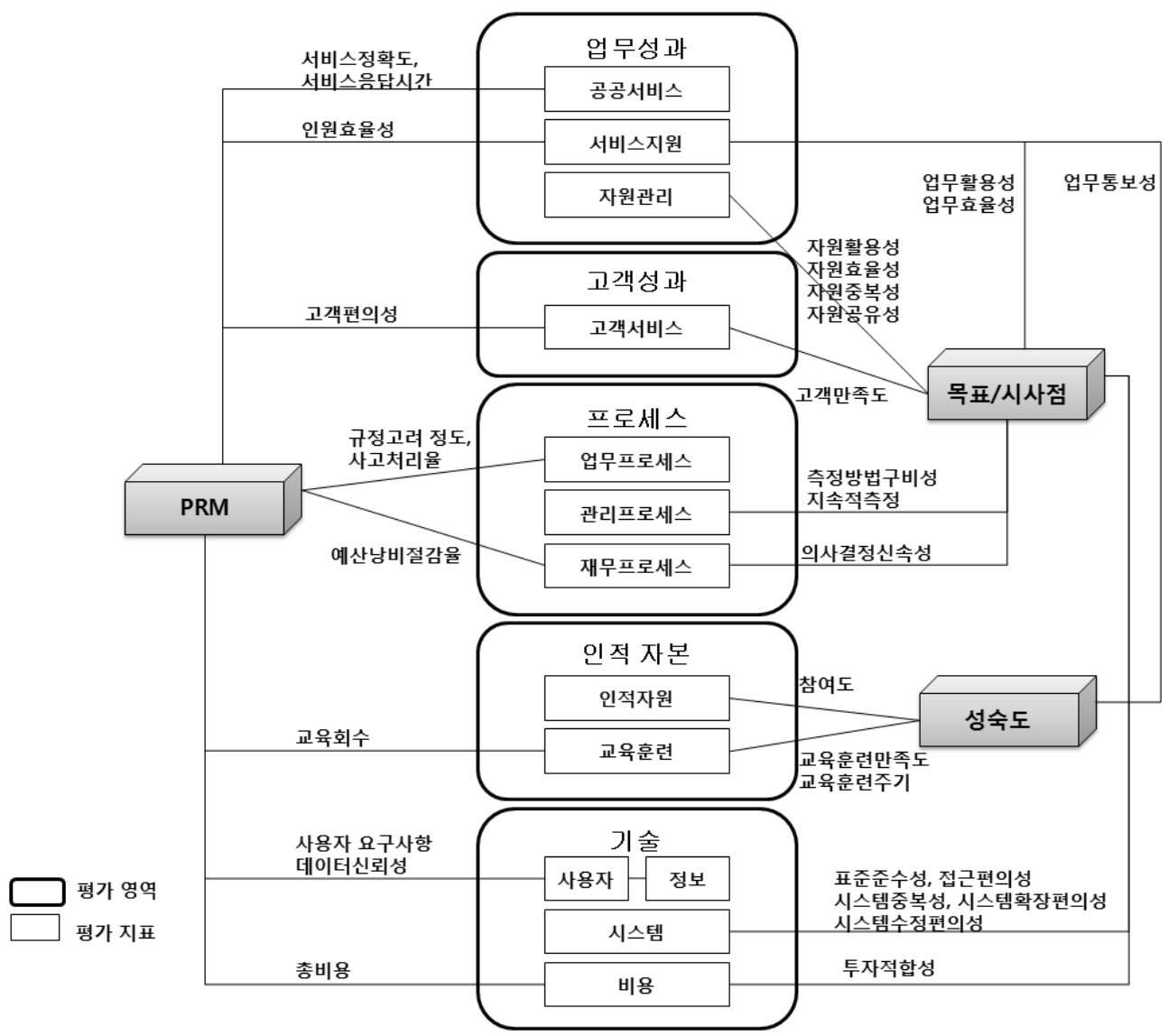

(그림 1) EA 성과평가 영역 및 평가 지표의 도출

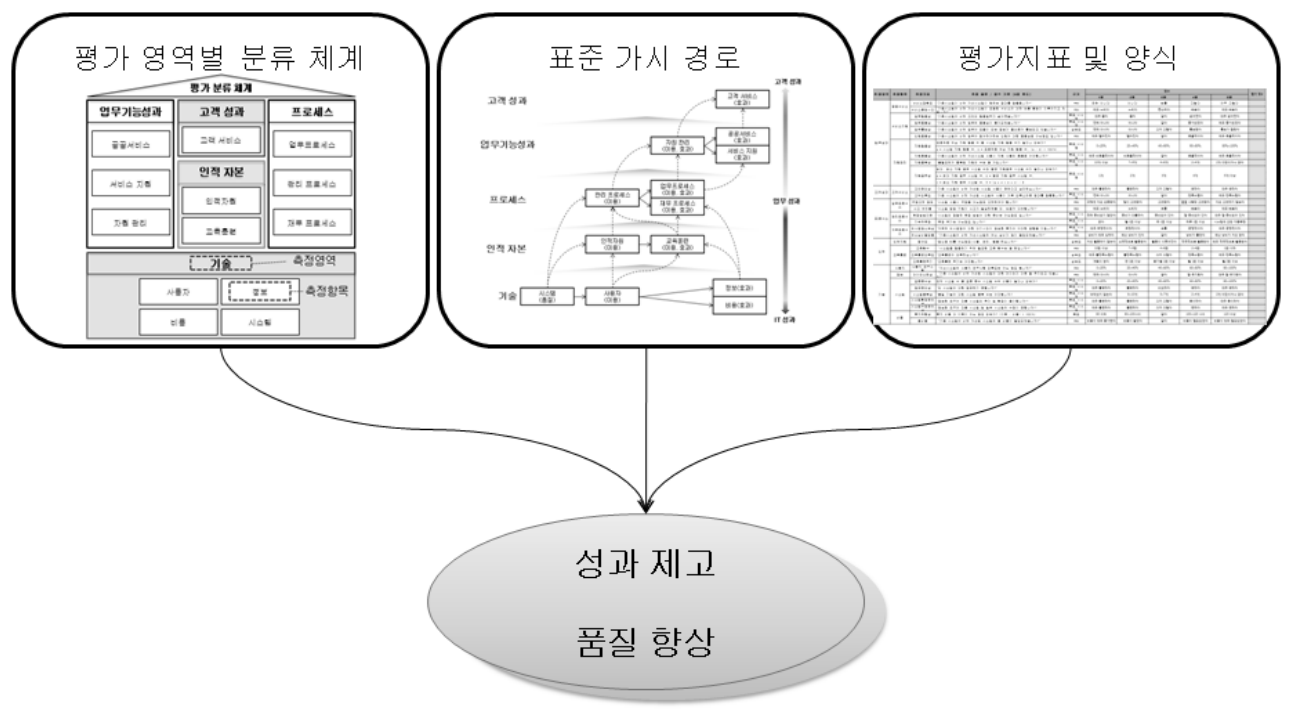

(그림 2) EA 성과평가 모델 프레임워크 
계, 가시경로, 성과평가 지표 및 양식으로 구성되며 최종적 으로는 성과 제고와 품질향상을 목표로 한다.

영역별 분류체계는 기관의 $\mathrm{EA}$ 현황에 맞게 평가지표를 도 출하기 위한 영역으로 구분된다. 가시경로란 평가 항목별로 평가지표간의 관계를 정의한 것으로 정보화사업의 성과가 조직의 업무 및 정책 성과로 연결될 수 있도록 돕는 역할을 한다. 성과평가 지표 및 양식은 각 영역별로 평가 지표와 기준 값, 목표 값 등에 대한 내용을 평가 지표로 작성할 수 있는 양식이다.

\subsubsection{EA 성과평가 모델의 영역별 분류 체계}

$\mathrm{EA}$ 성과평가 모델 영역별 분류 체계란 평가지표의 유형 별로 구분할 수 있도록 만든 체계로서 표준화된 성과평가 지표 개발 및 성과관리를 제공한다. 이러한 모델은 단계적 으로 평가영역 5 개, 평가항목 13 개로 구분되며 평가 항목 별 30 개의 평가지표로 구분된다. 평가영역은 업무기능성과, 고객성과, 프로세스, 인적자본 그리고 기술로 이루어져 있으 며 각 영역 분류 체계를 활용하여 평가지표를 제공하고 있 다. (그림 3)은 성과평가 모델의 영역별 분류 체계와 기존 $\mathrm{PRM}$ 과의 차이를 설명하고 있다. 기존 $\mathrm{PRM}$ 과의 차이는 고 객성과 영역의 고객과 서비스 항목을 결합해 고객서비스 항 목으로 구성하였고 기존 $\mathrm{PRM}$ 에서 개발 중인 인적자본의 영역 분류와 그에 따른 평가지표를 제시하였다. 또한 기술 영역의 정보화 항목은 업무기능성과와 고객영역으로 포함시 켰다.

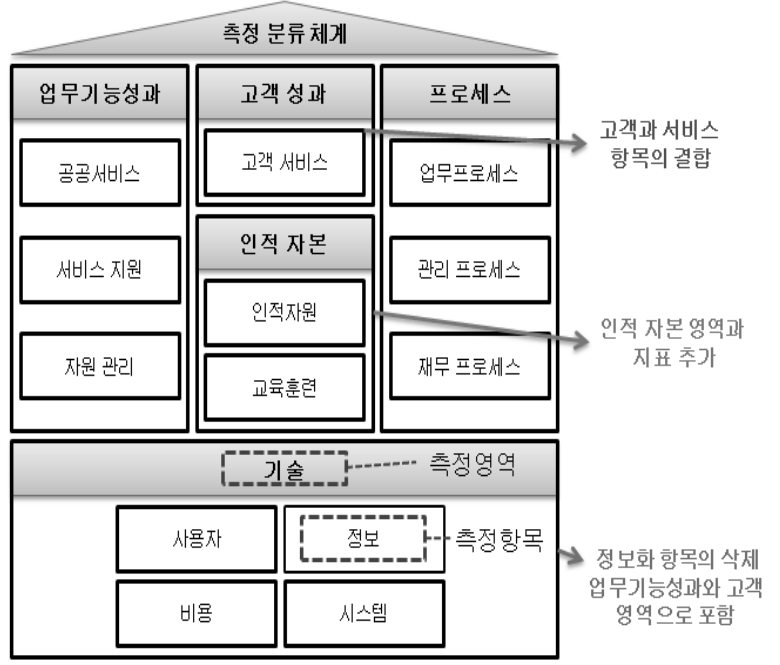

(그림 3) $\mathrm{EA}$ 성과평가 모델의 영역별 분류 체계

\subsection{2 $\mathrm{EA}$ 성과평가 모델 가시경로}

성과평가 모델 가시경로는 <표 2>의 평가 항목(3.2 절에 서 설명)에 대하여 각 평가 항목별로 3 가지 그룹(품질, 이용, 효과)으로 구분하였다. 각 그룹에 대한 구분 기준을 보면 평 가 항목내의 평가 지표가 어떠한 것의 품질에 대한 것인 경 우에 는 품질 지표로 분류하였으며, 이용에 관한 편의성 및
활용성에 대해서는 이용 지표로 분류하였다. 이러한 이용 지표를 통해 어떠한 효과를 발생하는 지를 평가하는 지표는 효과 지표로 분류하였다. 평가항목 중 이용 지표와 효과 지 표가 동시에 나타나는 지표들은 이용 지표와 효과 지표를 연결하는 다리 역할을 하는 지표이며 이를 이용 및 효과로 표현하였다. 이러한 지표는 (그림 4)와 같이 각 평가 영역별 로 구분하여 나타내었다. 가시 경로에 대한 평가 항목에 대 하여 각 항목은 IT 성과에서 업무 성과로 영향을 미치며 업 무성과 향상은 결국 고객성과로 영향을 주기 때문에 이에 따라 5 가지 평가영역 내의 평가 항목 사이의 관계를 표현하 였다. 실선은 같은 평가 영역 내에 관계를 나타낸 것이며, 점선은 다른 영역으로 영향을 미치는 관계를 나타낸 것이 다. 이는 다른 관점에서 보면 (그림4)에서와 같은 지표의 경 우 IT 관점에서 성과를 나타내며 이를 기반으로 시스템을 사용하는 업무적 성과가 중앙 부분에 도출되며 그림의 상단 에 위치한 지표의 경우 시스템으로써 고객이 얻는 성과로 나타낼 수 있다.

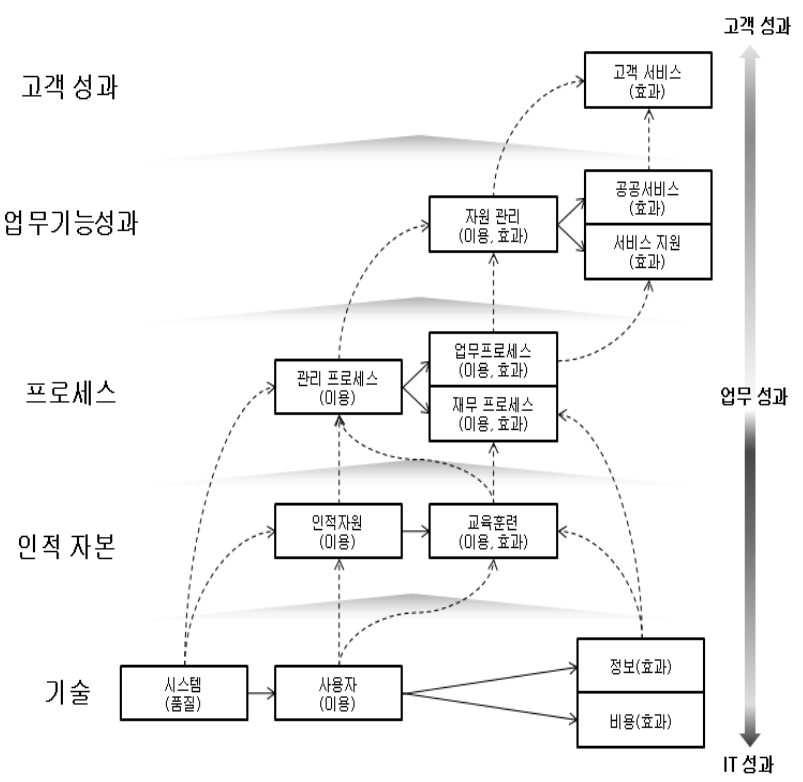

(그림 4) EA 성과평가모델 가시경로

\subsection{EA 평가지표}

$\mathrm{EA}$ 의 평가지표는 $\mathrm{EA}$ 에 대한 이해당사자의 인식을 기반 으로 하는 척도의 특성상 $\mathrm{EA}$ 의 이해당사자가 $\mathrm{EA}$ 를 활용 (구축, 운영)하면서 인식한 것에 대한 조사[16]를 할 수 있다 는 장점이 있다.

또한, 질문의 준비 기간과 그 결과를 빠르게 도출할 수 있다는 장점이 있으며 평가 인원수가 많을수록 평가 결과의 신뢰성이 증가하는 면을 보인다. EA에 대한 성과평가는 $\mathrm{EA}$ 및 정보시스템의 성과증진을 위한 개선지침을 도출하는데 중요한 기준이 된다[17]. 평가 항목별 평가 질문과 점수에 대한 정의는 <표 $2>$ 와 같다. 비고란은 각 평가지표가 도출 된 근거를 기술하였다. 
〈표 2〉 평가 영역별 평가항목 및 지표와 질문

\begin{tabular}{|c|c|c|c|c|}
\hline 평가 영역 & 평가 항목 & 평가 지표 & $\begin{array}{ll}\text { 평가 질문 / 점수 기준 (5점 척도) } \\
\end{array}$ & 비고 \\
\hline \multirow{10}{*}{$\begin{array}{l}\text { 업무 } \\
\text { 기능 } \\
\text { 성과 }\end{array}$} & \multirow{2}{*}{$\begin{array}{l}\text { 공공 } \\
\text { 서비스 }\end{array}$} & $\begin{array}{l}\text { 서비스 } \\
\text { 정확도 }\end{array}$ & $\begin{array}{l}\text { "기존 시스템에 비해 개선시스템이 원하는 결과를 정확히 제공합니까?” } \\
\text { 1점: 전혀 아님 5점: 매우 잘 이루어짐 }\end{array}$ & PRM \\
\hline & & $\begin{array}{l}\text { 서비스 } \\
\text { 응답시간 }\end{array}$ & $\begin{array}{l}\text { "기존 시스템에 비해 개선시스템이 요청한 서비스에 대해 빠른 응답이 이루어지고 있습니까?" } \\
\text { 1점: 매우 느림 5점: 매우 빠름 }\end{array}$ & PRM \\
\hline & \multirow{4}{*}{$\begin{array}{l}\text { 서비스 } \\
\text { 지원 }\end{array}$} & 업무 활용성 & $\begin{array}{l}\text { "기존 시스템에 비해 업무의 활용 범위가 넓어졌습니까?" } \\
\text { 1점: 전혀 아님 5점: 매우 증가됨 }\end{array}$ & $\mathrm{EA}$ 목적 \\
\hline & & 업무 효율성 & $\begin{array}{l}\text { "기존 시스템에 비해 업무의 효율성이 증가되었습니까?" } \\
\text { 1점: 전혀 아님 5점: 매우 증가됨 }\end{array}$ & $\mathrm{EA}$ 목적 \\
\hline & & 업무 통보성 & $\begin{array}{l}\text { "기존 시스템에 비해 업무에 도움이 되는 정보가 올바르게 통보되고 있습니까?" } \\
\text { 1점: 전혀 아님 5점: 잘 통보됨 }\end{array}$ & 성숙도 모델 \\
\hline & & 인원 효율성 & $\begin{array}{l}\text { "기존 시스템에 비해 업무에 참여해야 하는 인력에 대한 효율성은 어느 정도입니까?" } \\
\text { 1점: 매우 떨어짐 5점: 매우 효율적 }\end{array}$ & $\begin{array}{l}\mathrm{EA} \text { 목적 } \\
\mathrm{PRM}\end{array}$ \\
\hline & \multirow{4}{*}{ 자원관리 } & 자원 활용성 & $\begin{array}{ll}\mathrm{a}=\text { 시스템의 자원 활용 수 } & \mathrm{b}=\text { 프로젝트 예상 자원 활용 수 } \\
(\mathrm{a} / \mathrm{b}) \mathrm{X} 100(\%) & \\
\text { 1점: 0-20 5점: } 81-100 & \end{array}$ & $\mathrm{EA}$ 목적 \\
\hline & & 자원 효율성 & $\begin{array}{l}\text { "기존 시스템에 비해 개선시스템 사용시 자원 사용의 효율은 어떠합니까?" } \\
\text { 1점: 매우 비효율적 5점: 매우 효율적 }\end{array}$ & $\mathrm{EA}$ 목적 \\
\hline & & 자원 중복성 & $\begin{array}{l}\text { “불필요하게 중복된 자원의 수는 몇 개입니까?” } \\
\text { 1점: } 10^{+}, 2 \text { 점: 8-10,3:5-7, 4점: } 2-4 \text {, 5점: 중복 없음 }\end{array}$ & $\mathrm{EA}$ 목적 \\
\hline & & 자원 공유성 & $\begin{array}{ll}\mathrm{a}=\text { 최대 자원 공유 시스템 수 } & \mathrm{b}=\text { 평균 자원 공유 시스템 수 } \\
\mathrm{c}=\text { 최소 자원 공유 시스템 수 } & \mathrm{S}=(\mathrm{a}+4 \mathrm{x} \mathrm{b}+\mathrm{c}) / 6 \\
\text { 반올림 }(\mathrm{S})=\text { 점수, } 5 \text { 이상은 5점 } & \end{array}$ & $\mathrm{EA}$ 목적 \\
\hline \multirow{2}{*}{$\begin{array}{l}\text { 고객 } \\
\text { 성과 }\end{array}$} & \multirow{2}{*}{$\begin{array}{l}\text { 고객 } \\
\text { 서비스 }\end{array}$} & 고객 편의성 & $\begin{array}{l}\text { "기존 시스템에 비해 개선된 시스템의 사용이 편하다고 생각하십니까?" } \\
\text { 1점: 매우 불편함 5점: 매우 편함 }\end{array}$ & PRM \\
\hline & & 고객 만족도 & $\begin{array}{l}\text { "기존 시스템에 비해 개선된 시스템의 사용이 더 만족스러우십니까?" } \\
\text { 1점: 전혀 아님 5점: 매우 만족 }\end{array}$ & $\mathrm{EA}$ 목적 \\
\hline \multirow{6}{*}{$\begin{array}{l}\text { 프로 } \\
\text { 세스 }\end{array}$} & \multirow{2}{*}{$\begin{array}{l}\text { 업무 } \\
\text { 프로세스 }\end{array}$} & $\begin{array}{l}\text { 규정고려 } \\
\text { 정도 }\end{array}$ & $\begin{array}{l}\text { "시스템 사용 시 규정을 어느 정도 고려하여야 합니까?" } \\
\text { 1점: 뮤정에 거의 의존 5점: 거의 고려하지 않음 }\end{array}$ & PRM \\
\hline & & 사고 처리율 & $\begin{array}{l}\text { “시스템 담당 직원이 사고가 발생하였을 때, 빠르게 대처합니까?” } \\
\text { 1점: 매우 느림 5점: 매우 빠름 }\end{array}$ & PRM \\
\hline & \multirow{2}{*}{$\begin{array}{l}\text { 관리 } \\
\text { 프로세스 }\end{array}$} & $\begin{array}{l}\text { 평가방법 } \\
\text { 구비성 }\end{array}$ & $\begin{array}{l}\text { “시스템의 정량적 평가 방법에 대한 준비는 어느 정도입니까?” } \\
\text { 1점 전혀 준비되지 않음 5점 매우 잘 준비됨 }\end{array}$ & $\mathrm{EA}$ 목적 \\
\hline & & 지속적 평가 & $\begin{array}{l}\text { "측정 주기는 어느 정도입니까?" } \\
1 \text { 점: 계획 없음, } 2 \text { 점: } 1 \text { 달 } 1 \text { 회, } 3 \text { 점: } 1 \text { 주 } 1 \text { 회, } 4 \text { 점: } 1 \text { 일 } 1 \text { 회, } 5 \text { 점: 시스템에 의한 자동 측정 }\end{array}$ & $\mathrm{EA}$ 목적 \\
\hline & \multirow{2}{*}{$\begin{array}{l}\text { 재무 } \\
\text { 프로세스 }\end{array}$} & $\begin{array}{l}\text { 의사결정 } \\
\text { 신속성 }\end{array}$ & $\begin{array}{l}\text { “재무적 의사결정에 대한 대기 시간이 정보화 투자에 어떠한 영향을 미칩니까?” } \\
\text { 1점 매우 부정적 5점 매우 긍정적 }\end{array}$ & $\mathrm{EA}$ 목적 \\
\hline & & $\begin{array}{l}\text { 예산낭비 } \\
\text { 절감률 }\end{array}$ & $\begin{array}{l}\text { "기존 시스템에 비해 개선된 시스템으로 인해 예산이 많이 절감되었습니까?" } \\
\text { 1점: 낭비가 매우 심함 5점: 예산 낭비가 거의 없음 }\end{array}$ & PRM \\
\hline \multirow{3}{*}{$\begin{array}{l}\text { 인적 } \\
\text { 자본 }\end{array}$} & 인적자원 & 참여도 & $\begin{array}{l}\text { "당신은 } \mathrm{EA} \text { 를 어느 정도(사용, 관리, 활용)하십니까?” } \\
\text { 1점: 거의 사용하지 않음 5점: 매우 적극적 }\end{array}$ & 성숙도 모델 \\
\hline & \multirow{2}{*}{ 교육훈련 } & $\begin{array}{l}\text { 교육훈련 } \\
\text { 만족도 }\end{array}$ & $\begin{array}{l}\text { “교육 훈련에 만족하십니까?” } \\
\text { 1점 매우 불만족 5점 매우 만족 }\end{array}$ & 성숙도 모델 \\
\hline & & $\begin{array}{l}\text { 교육훈련 } \\
\text { 주기 }\end{array}$ & $\begin{array}{l}\text { "교육 훈련 주기는 어떠합니까?" } \\
\text { 1점: 계획 없음, } 2 \text { 점: } 1 \text { 년 } 1 \text { 회, } 3 \text { 점: 분기 } 1 \text { 회, } 4 \text { 점: 월 } 1 \text { 회, } 5 \text { 점: 그 이상 }\end{array}$ & 성숙도 모델 \\
\hline \multirow{9}{*}{ 기술 } & 사용자 & $\begin{array}{l}\text { 사용자 } \\
\text { 요구사항 }\end{array}$ & $\begin{array}{l}\text { "개선 시스템의 사용자 요구사항 만족도는 어느 정도 됩니까?" } \\
\text { 1점: 0-20\% 5점: 80-100\% }\end{array}$ & PRM \\
\hline & 정보 & $\begin{array}{l}\text { 데이터 } \\
\text { 신뢰성 }\end{array}$ & $\begin{array}{l}\text { "기존 시스템에 비해 개선된 시스템에 대한 데이터가 더욱 잘 유지되고 있습니까?" } \\
\text { 1점: 전혀 아님 5점: 매우 잘 유지됨 }\end{array}$ & PRM \\
\hline & \multirow{5}{*}{ 시스템 } & 표준 준수성 & $\begin{array}{l}\text { (표준 준수 시스템 수 / 전체 시스템 수) × 100(\%) } \\
\text { 1점: 0-20 5점: 81-100 }\end{array}$ & $\mathrm{EA}$ 목적 \\
\hline & & 접근 편의성 & $\begin{array}{l}\text { "타 시스템에 접근하기가 편리해 졌습니까?" } \\
\text { 1점 매우 불편함 5점 매우 편리함 }\end{array}$ & EA 목적 \\
\hline & & $\begin{array}{l}\text { 시스템 } \\
\text { 중복성 }\end{array}$ & $\begin{array}{l}\text { "동일 기능에 대한 시스템 중복 수는 어떠합니까?" } \\
\text { 1점: 파악불가, } 2 \text { 점: } 10 ~ 8,3 \text { 점: } 7 \sim 5 \text {, 4점: } 4 \sim 2,5 \text { 점: 중복없음 }\end{array}$ & $\mathrm{EA}$ 목적 \\
\hline & & $\begin{array}{l}\text { 시스템 확장 } \\
\text { 편의성 }\end{array}$ & $\begin{array}{l}\text { “정보화 요구에 따른 시스템의 추가 및 확장이 용이합니까?” } \\
\text { 1점: 매우 불편함 5점: 매우 용이함 }\end{array}$ & EA 목적 \\
\hline & & $\begin{array}{l}\text { 시스템 수정 } \\
\text { 편의성 }\end{array}$ & $\begin{array}{l}\text { "정보화 요구에 따른 시스템 및 일부 시스템의 수정이 편리합니까?" } \\
\text { 1점: 매우 불편함 5점: 매우 편리함 }\end{array}$ & EA 목적 \\
\hline & \multirow{2}{*}{ 비용 } & 투자 적합성 & $\begin{array}{l}\text { (이득 / 비용) X } 100(\%) \\
\text { 1점: } 100 \text { 미만, } 3 \text { 점: } 100,5 \text { 점: } 100 \text { 이상 }\end{array}$ & $\mathrm{EA}$ 목적 \\
\hline & & 총비용 & $\begin{array}{l}\text { "기존 시스템에 비해 개선된 시스템의 총 비용이 절감되었습니까?" } \\
\text { 1점: 매우 증가함 5점: 매우 절감됨 }\end{array}$ & PRM \\
\hline
\end{tabular}




\section{$3.3 \mathrm{EA}$ 평가 지표 및 개선지침}

제안한 성과평가 모델은 5점 척도에 따라서 개인이 인지 하고 있는 $\mathrm{EA}$ 에 대한 의견이나 생각 및 판단을 평가할 수 있다. 이러한 평가는 $\mathrm{EA}$ 및 정보시스템에 대한 태도에 영향 을 주고 이는 결국 개인이 $\mathrm{EA}$ 및 정보시스템을 통해 얻는 성과에 영향을 미치게 된다 $[16,18]$. 본 논문에서 제안하고자 하는 평가모델은 이해당사자의 $\mathrm{EA}$ 에 대한 인식을 평가하여 얻어진 결과를 정량적인 평가기준으로 정의하여 각 평가점 수에 대한 기준을 수립하고 상위 수준으로 $\mathrm{EA}$ 를 발전시켜 나가기 위한 방법을 제공할 수 있게 하였다. 이러한 발전 방법에 대한 지침을 마련하기 위해 우선 <표 $3>$ 와 같이 각 수준별 기준을 마련하였다.

점수 1 은 인식 단계이다. 이 단계는 평가의 필요성은 인 식하고 있으나 실제로 수행은 하고 있지 못하는 단계로 $\mathrm{EA}$ 및 시스템의 도입 초기 단계에 $\mathrm{EA}$ 를 적용하고 활용하려는 단계를 말한다.

점수 2 는 설정 및 수행 단계로써 각 평가 지표별 목적과 평가 요소를 $\mathrm{EA}$ 수준에서 정의하고 평가를 수행하는 단계 이다. $\mathrm{EA}$ 의 적응과 활용도는 높으나 오류 사항이 빈번하고

〈표 3〉EA의 평가 지표별 점수 기준

\begin{tabular}{|c|c|}
\hline 점수 & 기준 \\
\hline $\begin{array}{c}1 \\
\text { (인식) }\end{array}$ & $\begin{array}{l}\text { - 평가 지표를 측정할 수 있는 방법이나 평가 요소가 } \\
\text { 존재하지 않는다. } \\
\text { - 평가의 필요성은 느끼나 평가하고 있지 않다. } \\
\text { - 평가 요소에 대해서 } \mathrm{EA} \text { 수준으로 정의하거나 관리 } \\
\text { 하지 않는다. }\end{array}$ \\
\hline $\begin{array}{c}2 \\
\text { (설정 및 } \\
\text { 수행) }\end{array}$ & $\begin{array}{l}\text { - 평가 요소를 비정규적이고 간헐적으로 평가하고 있다. } \\
\text { - 평가 지표별 평가 요소를 식별하였다. } \\
\text { - EA 수준에서 평가 지표별 정량적 목표를 설정하고 } \\
\text { 있다. }\end{array}$ \\
\hline $\begin{array}{c}3 \\
\text { (만족) }\end{array}$ & $\begin{array}{l}\text { - EA 수준에서 만족하는 평가 결과를 가진다. } \\
\text { - 개선의 필요성을 인식하고 개선을 수행하고 있으나 } \\
\text { 비정규적, 간헐적, 즉흥적으로 수행하고 있다. } \\
\text { - 예측의 필요성을 인식하고는 있으나 예측을 하지 } \\
\text { 못한다. }\end{array}$ \\
\hline $\begin{array}{c}4 \\
\text { (예측과 } \\
\text { 관리) }\end{array}$ & $\begin{array}{l}\text { - 개선에 따른 평가 요소별 예측을 수행한다. } \\
\text { - 문제와 개선, 피드백 등을 } \mathrm{EA} \text { 수준에서 기록 및 관 } \\
\text { 리하고 있다. } \\
\text { - 기록된 내용을 향후 유사 문제에 활용한다. } \\
\text { - 유동적 변경 및 개선 절차가 존재한다. }\end{array}$ \\
\hline $\begin{array}{c}5 \\
\text { (자동화 } \\
\text { 및 } \\
\text { 최적화) }\end{array}$ & $\begin{array}{l}\text { - 평가를 시스템 수준에서 자동으로 수행한다. } \\
\text { - 평가에 변동사항을 시스템 수준에서 이해당사자에 } \\
\text { 게 자동으로 통보한다. } \\
\text { - 지속적 개선 계획과 개선 절차가 존재한다. }\end{array}$ \\
\hline
\end{tabular}

이에 대처하는데 많은 인력과 자원이 투입되어 실제 평가에 투입되는 노력과 자원이 상대적으로 적은 수준을 의미한다. 또한 상위 수준에서 측정 및 평가의 필요성을 $\mathrm{EA}$ 수준으로 정의하고 있는 단계를 의미한다.

점수 3 은 만족 단계이다. 이 단계는 $\mathrm{EA}$ 의 도입 목적에 적합한 수준으로 $\mathrm{EA}$ 가 성과를 발생하는 단계를 의미한다. 이 단계에서 시스템은 초기에 설정한 목표를 달성하고 있으 나 지속적인 개선과 오류가 발생하고 있으며, 이를 탐지할 수 있는 방법을 $\mathrm{EA}$ 수준에서 명문화하여 $\mathrm{EA}$ 를 사용하는 이해당사자들이 적용할 수 있는 수준을 의미한다.

점수 4 는 예측과 관리 단계이다. 이 단계는 더 많고 좋은 성과를 발생하기 위해 $\mathrm{EA}$ 의 지속적인 개선을 수행하고 있 으며 이러한 개선이 어떠한 결과를 나타낼 수 있는지 예측 할 수 있는 단계를 의미한다. 이러한 예측의 오차 범위는 각 조직마다 다를 수 있으나 일반적으로 $5 \%$ 유의수준에 만 족하는 것을 원칙으로 한다. 또한 이러한 개선의 원인과 해 결 및 피드백을 기록하여 전반적인 성과 증진과 목표 달성 을 위해 $\mathrm{EA}$ 를 관리한다.

점수 5 는 자동화와 최적화 단계이다. 이 단계는 $\mathrm{EA}$ 가 궁 극적으로 도달해야하는 단계를 의미한다. 대부분이 시스템 수준에서 자동적으로 수행되고 있으며 평가 결과가 특정 유 의 수준에서 벗어나거나 목표 수준에 도달하였을 때 이해당 사자에게 자동적으로 통보할 수 있는 자동화가 첫 번째 목 표이다. 두 번째는 각 평가 목표 달성의 결과를 최적화하기 위해 지속적인 개선을 수행하는 최적화를 의미한다.

이러한 기준으로 마련한 $\mathrm{EA}$ 평가 지표별 평가요소 및 점 수별 개선지침은 <표 $4>$, <표 $5>$ 와 같다. 평가지표를 설명 하기 위해 각 점수별 기준을 근거로 평가 요소를 도출하였 다. 아울러 논문 지면상 모든 평가요소를 모두 다 표현하지 는 못했다.

〈표 4〉EA 평가 지표별 평가요소

\begin{tabular}{|c|l|}
\hline 평가지표 & \multicolumn{1}{|c|}{ 평가 요소 } \\
\hline \hline \multirow{2}{*}{ 서비스 } & $\mathrm{ER}=\mathrm{EA}$ 에 정해진 서비스의 오류 개수 \\
정확도 & $\mathrm{EA}=$ 보고된 실제 발생 서비스 오류 개수 \\
& $\mathrm{EE}=$ 향후 발생 오류 개수의 예측 \\
\hline \multirow{3}{*}{ 서비스 } & $\mathrm{TR}=\mathrm{EA}$ 에 정해진 특정 서비스 응답시간 \\
응답시간 & $\mathrm{TA}=$ 실제 특정 서비스 응답 시간 \\
& $\mathrm{CTA}=$ 보고된 응답 시간이 초과한 서비스의 개수 \\
& $\mathrm{ECTA}=$ 응답 시간 초과 서비스 개수의 예측 \\
\hline \multicolumn{2}{|c}{} \\
\hline
\end{tabular}

〈표 5〉EA 평가 지표의 각 점수별 개선 지침

\begin{tabular}{|c|c|c|c|c|}
\hline 측정 지표 & 1점 $->2$ 점 개선 지침 & 2점 $->3$ 점 개선 지침 & 3점 $->4$ 점 개선 지침 & 4 점 $->5$ 점 개선 지침 \\
\hline $\begin{array}{l}\text { 서비스 } \\
\text { 정확도 }\end{array}$ & $\begin{array}{l}\text { 1. } \mathrm{ER}, \mathrm{EA} \text { 를 측정하고 있다. } \\
\text { 2. } \mathrm{ER}<\mathrm{EA} \\
\text { 3. } \mathrm{EE} \text { 를 예측하지 못한다. }\end{array}$ & $\begin{array}{l}\text { 1. } \mathrm{ER}>=\mathrm{EA} \\
\text { 2. } \mathrm{EE} \text { 를 예측하지 못한다. }\end{array}$ & 1. $\mathrm{EE}$ 를 예측한다. & $\begin{array}{l}\text { 1. } \mathrm{EE} \text { 의 감소를 위한 지속적 } \\
\text { 개선 절차가 존재한다. }\end{array}$ \\
\hline $\begin{array}{l}\text { 서비스 } \\
\text { 응답시간 }\end{array}$ & $\begin{array}{l}\text { 1. TR, TA, CTA를 측정하고 } \\
\text { 있다. } \\
\text { 2. CTA < ER } \\
\text { 3. ECTA를 예측하지 못한다. }\end{array}$ & $\begin{array}{l}\text { 1. } \mathrm{CTA}>=\mathrm{ER} \\
\text { 2. ECTA를 예측하지 못한다. }\end{array}$ & 1. ECTA를 예측한다. & $\begin{array}{l}\text { 1. ECTA의 감소를 위한 지속 } \\
\text { 적 개선 절차가 존재한다. }\end{array}$ \\
\hline
\end{tabular}


예를 들어, 서비스 정확도의 경우 서비스 정확도를 표현 할 수 있는 오류의 개수를 고려하여 $\mathrm{EA}$ 수준에서 설정된 오류의 개수, 실제 정보시스템에서 발생된 오류의 개수와 점수 4점 기준에 필요한 오류 개수의 예측 부분을 도출한 것이다.

\section{4. 적용사례를 통한 검증}

본 장에서는 제안 하고자 하는 $\mathrm{EA}$ 성과평가 모델의 적용 성과 유용성을 검증하기 위해 3 개 기관에 적용하여 성과평 과를 평가하였고 그 결과의 제시 및 기존 모델들과의 상이 점을 비교 평가하였다.

\section{1 적용성 검증을 위한 평가}

본 장에서는 정부 부처 중 3 개 기관 $(\mathrm{B}$ 기관, $\mathrm{C}$ 기관, $\mathrm{D}$ 기 관)에서 운영 중인 $\mathrm{EA}$ 를 기반으로 기존의 범정부 $\mathrm{EA}$ 성숙 도 모델의 성과관리 영역과 본 연구에서 제안한 $\mathrm{EA}$ 성과평 가 모델을 적용하여 평가한 결과를 비교분석하여 본 연구에 서 제안한 성과평가 모델의 적용성을 검증하고자 한다.

<표 6>은 $\mathrm{B}$ 기관의 범정부 $\mathrm{EA}$ 성숙도 모델에서 제안한 성과평가모델을 적용하여 성과 평가한 결과이다. 평가 결과 의 양이 방대하기 때문에 일부 평가 결과만 기술하였다. 서 비스 정확도 및 서비스 응답시간의 평가지표에 대한 평가 결과는 각 2 점 이었으며, 평가 결과의 산술평균 값(반올림) 이 공공 서비스 평가항목의 평가 결과가 된다. 그리고 각 평가 항목(공공 서비스, 서비스 지원, 자원 관리)의 산술평 균 값(반올림)의 결과가 평가 영역(업무기능성과)에 대한 평
〈표 6〉B기관의 $\mathrm{EA}$ 성과평가모델의 성과평가 결과

\begin{tabular}{|c|c|c|c|}
\hline 평가영역 & 평가항목 & 평가 지표 & 평가 점수 \\
\hline \multirow{6}{*}{$\begin{array}{c}\text { 업무기능 } \\
\text { 성과 } \\
(2.4)\end{array}$} & \multirow{2}{*}{$\begin{array}{c}\text { 공공서비스 } \\
(2.0)\end{array}$} & 서비스 정확도 & 2 \\
\hline & & 서비스 응답시간 & 2 \\
\hline & \multirow{2}{*}{$\begin{array}{c}\text { 서비스지원 } \\
(2.3)\end{array}$} & 업무 활용성 & 2 \\
\hline & & $\ldots$ & $\ldots$ \\
\hline & \multirow{2}{*}{$\begin{array}{c}\text { 자원관리 } \\
\text { (3.0) }\end{array}$} & 자원 활용성 & 3 \\
\hline & & $\ldots$ & \\
\hline & & & \\
\hline
\end{tabular}

가 결과 값이 된다.

<표 7>은 3개 기관에 범정부 EA성숙도 모델의 성과관리 영역과 제안한 성과평가 모델의 평가영역을 적용하여 평가 한 결과를 기술한 것이다.

범정부 $\mathrm{EA}$ 성숙도 모델(성과관리영역)을 적용한 결과는 각 기관별로 $1,2,1$ 점으로 산출되었다. 제안한 성과평가 모 델과 다른 결과로 나타난 이유는 범정부 $\mathrm{EA}$ 성숙도 모델은 성과관리영역 평가에 대한 평가요소가 미흡하며, 평가방법 구비성 및 지속적 평가만을 고려하고 있기 때문이다. 그리 고 범정부 $\mathrm{EA}$ 성숙도 모델에서는 표준 준수와 규정고려의 경우 관리 영역에 포함되어 성과관리 영역과는 별개의 영역 으로 다루고 있다

그러나 제안한 성과평가 모델의 경우 성과평가를 위해 $\mathrm{EA}$ 의 특징 및 $\mathrm{PRM}$ 등을 기반으로 한 평가요소를 제안하 였기 때문에 <표 8>과 같이 자세한 평가 결과를 얻을 수 있는 것이다.

두 번째 이유는 개선 지침에 따른 차이이다. 본 연구에서

〈표 7〉범정부 EA성숙도 모델과 제안한 성과평가 모델의 성과 평가 결과

\begin{tabular}{|c|c|c|c|}
\hline 구분 & 범정부 EA 성숙도 모델 (성과관리영역) & 제안한 & \\
\hline \multirow{6}{*}{$\mathrm{B}$ 기관 } & \multirow{6}{*}{ " } & 업무기능성과* & 2.4 \\
\hline & & 고객성과 & 2.5 \\
\hline & & 프로세스 & 2.6 \\
\hline & & 인적자본 & 2.5 \\
\hline & & 기술 & 2.8 \\
\hline & & 종합 & 2.7 \\
\hline \multirow{6}{*}{$\mathrm{C}$ 기관 } & \multirow{6}{*}{2} & 업무기능성과 & 3.4 \\
\hline & & 고객성과 & 3.1 \\
\hline & & 프로세스* & 2.7 \\
\hline & & 인적자본 & 3.4 \\
\hline & & 기술 & 3.4 \\
\hline & & 종합 & 3.2 \\
\hline \multirow{6}{*}{$\mathrm{D}$ 기관 } & \multirow{6}{*}{1} & 업무기능성과 & 2.8 \\
\hline & & 고객성과 & 3.5 \\
\hline & & 프로세스" & 2.1 \\
\hline & & 인적자본 & 3.0 \\
\hline & & 기술 & 2.9 \\
\hline & & 종합 & 2.9 \\
\hline
\end{tabular}

* EA 성숙도모델에서 성과관리 항목은 제안한 성과평가 모델의 프로세스 영역 하위의 관리프로세스 항목에 포함됨. 
제안한 평가모델의 개선 지침은 <표 4>와 <표 5>에서 알 수 있듯이 일관된 기준을 근거로 그 지침을 마련한 것이다. 그러나 범정부 성숙도 모델의 경우에는 각 성숙 수준에 따 라 지침이 다를 뿐만 아니라 각 성숙도 수준별로도 별개의 점수가 존재한다.

즉, 제안한 성과평가 모델은 기준이 유사하기 때문에 성 과와 관련된 평가요소의 평가와 그 결과의 개선을 위한 지 침으로 일관성 있게 구성되어 있으나 범정부 $\mathrm{EA}$ 성숙도 모 델의 경우에는 $\mathrm{EA}$ 를 성숙시키기 위한 지침이 대부분으로 제안한 성과평가 모델과는 다소 차이가 있음을 알 수 있다.

\section{2 유용성 검증을 위한 평가 및 개선지침}

본 연구에서 제안한 $\mathrm{EA}$ 성과평가 모델의 개선 지침을 기 반으로 <표 7>에서 도출된 결과를 적용하여 다음과 같은 개선지침의 활용 방법을 기술하였다.

\subsubsection{EA 성과 향상을 위한 개선 지침}

$<$ 표 7>에서 $\mathrm{B}$ 기관의 $\mathrm{EA}$ 를 평가한 결과는 평균 2.7점으 로 평가되었다. <표 5>에서 제안한 개선지침을 기반으로 $\mathrm{B}$ 기관의 성과를 3 점으로 향상시키기 위해 개선해야 할 평가 지표에 대한 개선 지침을 <표 8>와 같이 도출하여 제안한 모델의 유용성을 검증하였다.

\subsection{2 지속적 성과향상을 위한 지침}

본 연구에서 제안한 $\mathrm{EA}$ 성과평가 모델은 $\mathrm{EA}$ 의 지속적 성 과향상을 위해 다음과 같이 확장할 수 있다. 첫째, $\mathrm{EA}$ 의 성 과를 제안한 성과평가 모델을 이용하여 지속적으로 평가한 다. 둘째, 평균 점수에 미치지 못하거나 또는 향상이 요구되 는 지표를 식별하고 도달하고자 하는 목표를 정의하여 $\mathrm{EA}$ 수준에서 명시한다. 셋째, 요소를 평가하고 결과를 개선하기 위한 방법과 절차를 $\mathrm{EA}$ 수준에서 명문화한다. 마지막으로 마련한 방법과 절차에 따라 시스템을 개선한다.

이러한 지침은 지속적이고 주기적으로 반복되어야 한다. 또한 4 5점의 평가를 얻었다면 추가적인 평가 지표와 평가 요소를 개발하고 도출하여 본 연구에서 제안한 $\mathrm{EA}$ 성과평 가 모델을 확장 및 발전시켜 나가야 할 것이다.

4.3 기존 모델들과의 비교

앞에서도 언급했듯이 현재는 $\mathrm{EA}$ 에 대한 성과평가 모델이
존재하지 않으며 이에 대한 연구도 미흡한 실정이다. 따라 서 $\mathrm{EA}$ 성숙도에서 도출할 수 있는 성과평가 지표와 $\mathrm{PRM}$ 에 서 제시한 성과평가 지표 및 본 연구에서 제안한 성과평가 모델의 성과평가 지표에 대한 상호 비교를 통해 본 연구의 특-장점을 도출하고자 한다. 각 모델들에 대한 성과평가 지표에 대한 비교는 <표 9>와 같다.

<표 9>의 비교를 통해 기존 모델들과의 상이점 등을 살 펴보면 첫째, $\mathrm{EA}$ 성숙도의 경우에는 활용 영역에 성과관리 영역이 포함되어 있으며 $\mathrm{EA}$ 의 성과평가에 대한 세부적인 지침은 존재하지 않으나 평가 지표와 지속적인 평가에 대한 언급은 있다. 또한 표준을 준수하였는지 규정은 어느 정도 준수 하였는지에 대해서만 언급하고 있다.

둘째, 범정부 PRM에서는 본 논문에서 많은 평가지표를 도출하여 활용하였다. 그러나 $\mathrm{PRM}$ 은 $\mathrm{EA}$ 의 특징 및 $\mathrm{EA}$ 를 통해 얻는 장점에 대한 성과지표가 상당 수 들어 있지 않았 다. 또한 평가를 위한 세부지표가 존재하지 않아 기관별로 특성 있는 지표를 적용하기 어려운 단점이 있다. 그러므로 $\mathrm{PRM}$ 과 본 논문에서 제안한 성과평가 모델의 차이는 $\mathrm{EA}$ 의 특징에서 도출한 평가지표에 대한 차이로 나타났다.

마지막으로 정보화 성과평가 모델에서는 $\mathrm{EA}$ 의 도입 및 성과에 대한 효과 평가 기준 및 관점은 제시하고 있으나 실 질적인 세부 지표 및 측정 방법은 역시 존재하지 않았다.

\section{4 $\mathrm{PRM}$ 과의 비교를 통한 지표의 필요성}

본 연구의 기반이 되는 $\mathrm{PRM}$ 과 제안 모델을 $\mathrm{B}, \mathrm{C}, \mathrm{D}$ 기 관에 적용하여 평가한 결과를 살펴보면 $\mathrm{PRM}$ 의 경우는 각 기관별로 $2.9 / 3.4 / 2.9$ 점이 나왔으며, 개선 지표로 도출된 것 은 각각 $4 / 4 / 3$ 개이다. 그러나 본 연구에서 제안한 모델의 경 우에는 각각 2.7/3.2/2.9 점이 나왔으며, 개선 지표는 각각 $9 / 13 / 5$ 개씩이다. 개선지표는 평균보다 낮은 점수를 얻은 지 표를 선정한 것이다. 이의 적용 결과는 <표 10>과 같다.

측정 결과 다음과 같은 해석을 할 수 있다. 첫째, 제안 모 델은 PRM에서 도출된 개선 지표를 포함하고 있다. 이는 제 안 모델이 PRM의 지표를 수용하였기 때문이다. 둘째, 제안 모델은 PRM 보다 많은 성과지표를 제공한다. 여기서 주의 해야 할 것은 개선지표 중 <표 10>에서 Bold체로 표기한 지표들이다. 이는 각 기관에서 우선적으로 개선해야 할 지 표(평가 결과, 가장 낮은 점수 획득)임에도 불구하고 $\mathrm{PRM}$ 은 이를 도출하지 못하거나 부분적으로 도출하였다. 이는

〈표 8〉B기관의 $\mathrm{EA}$ 성과 향상(2점 $\rightarrow 3$ 점)을 위한 평가지표에 대한 개선지침

\begin{tabular}{|c|c|c|c|c|}
\hline 평가 영역 & 평가 항목 & 평가 지표 & 평가 요소 및 약어 설명 & 개선지침 \\
\hline \multirow{2}{*}{$\begin{array}{l}\text { 업무 } \\
\text { 성과 }\end{array}$} & \multirow[b]{2}{*}{ 공공 서비스 } & $\begin{array}{l}\text { 서비스 } \\
\text { 정확도 }\end{array}$ & $\begin{array}{l}\mathrm{ER}=\mathrm{EA} \text { 에 정해진 서비스의 오류 개수 } \\
\mathrm{EA}=\text { 보고된 실제 발생 서비스 오류 개수 } \\
\mathrm{EE}=\text { 향후 발생 오류 개수의 예측 }\end{array}$ & $\begin{array}{l}\text { 1. } \mathrm{ER}>=\mathrm{EA} \\
\text { 2. } \mathrm{EE} \text { 를 예측하지 못한다. }\end{array}$ \\
\hline & & $\begin{array}{l}\text { 서비스 } \\
\text { 응답 } \\
\text { 시간 }\end{array}$ & $\begin{array}{l}\mathrm{TR}=\mathrm{EA} \text { 에 정해진 특정 서비스 응답시간 } \\
\mathrm{TA}=\text { 실제 특정 서비스 응답 시간 } \\
\mathrm{CTA}=\text { 보고된 응답 시간이 초과한 서비스의 개수 } \\
\mathrm{ECTA}=\text { 응답 시간 초과 서비스 개수의 예측 }\end{array}$ & $\begin{array}{l}\text { 1. } \mathrm{CTA}>=\mathrm{ER} \\
\text { 2. } \mathrm{ECTA} \text { 를 예측하지 못한다. }\end{array}$ \\
\hline$\ldots$ & $\ldots$ & $\ldots$ & $\ldots$ & $\ldots$ \\
\hline
\end{tabular}


〈표 9〉기존 모델의 성과평가 지표와 비교

\begin{tabular}{|c|c|c|c|c|c|}
\hline \multicolumn{3}{|c|}{ 제안한 성과평가모델 } & \multirow{2}{*}{$\begin{array}{c}\mathrm{EA} \text { 성숙도 } \\
\text { 모델 }\end{array}$} & \multirow[b]{2}{*}{ PRM } & \multirow{2}{*}{$\begin{array}{l}\text { 제안 } \\
\text { 모델 }\end{array}$} \\
\hline $\begin{array}{l}\text { 평가 } \\
\text { 영역 }\end{array}$ & 평가항목 & 평가 지표 & & & \\
\hline \multirow{10}{*}{$\begin{array}{l}\text { 업무 } \\
\text { 기능 } \\
\text { 성과 }\end{array}$} & \multirow{2}{*}{ 공공서비스 } & 서비스 정확도 & & $\mathrm{O}$ & $\mathrm{O}$ \\
\hline & & 서비스 응답시간 & & $\mathrm{O}$ & $\mathrm{O}$ \\
\hline & \multirow{4}{*}{ 서비스지원 } & 업무 활용성 & & $\mathrm{O}$ & $\mathrm{O}$ \\
\hline & & 업무 효율성 & & $\mathrm{O}$ & $\mathrm{O}$ \\
\hline & & 업무 통보성 & & & $\mathrm{O}$ \\
\hline & & 인원 효율성 & & $\mathrm{O}$ & $\mathrm{O}$ \\
\hline & \multirow{4}{*}{ 자원관리 } & 자원 활용성 & & & $\mathrm{O}$ \\
\hline & & 자원 효율성 & & & $\mathrm{O}$ \\
\hline & & 자원 중복성 & & & $\mathrm{O}$ \\
\hline & & 자원 공유성 & & $\mathrm{O}$ & $\mathrm{O}$ \\
\hline \multirow{2}{*}{$\begin{array}{l}\text { 고객 } \\
\text { 성과 }\end{array}$} & \multirow{2}{*}{ 고객서비스 } & 고객 편의성 & & $\mathrm{O}$ & $\mathrm{O}$ \\
\hline & & 고객 만족도 & & $\mathrm{O}$ & $\mathrm{O}$ \\
\hline \multirow{6}{*}{$\begin{array}{l}\text { 프로 } \\
\text { 세스 }\end{array}$} & \multirow{2}{*}{ 업무프로세스 } & 규정고려 정도 & $\triangle$ & & $\mathrm{O}$ \\
\hline & & 사고 처리율 & & & $\mathrm{O}$ \\
\hline & \multirow{2}{*}{ 관리프로세스 } & 평가방법구비성 & $\mathrm{O}$ & & $\mathrm{O}$ \\
\hline & & 지속적 평가 & $\mathrm{O}$ & & $\mathrm{O}$ \\
\hline & \multirow{2}{*}{ 재무프로세스 } & 의사결정 신속성 & & & $\mathrm{O}$ \\
\hline & & 예산낭비 절감률 & & $\mathrm{O}$ & $\mathrm{O}$ \\
\hline \multirow{3}{*}{$\begin{array}{l}\text { 인적 } \\
\text { 자본 }\end{array}$} & 인적자원 & 참여도 & & & $\mathrm{O}$ \\
\hline & \multirow{2}{*}{ 교육훈련 } & 교육훈련만족도 & & & $\mathrm{O}$ \\
\hline & & 교육훈련주기 & & & $\mathrm{O}$ \\
\hline \multirow{9}{*}{ 기술 } & 사용자 & 사용자 요구사항 & & $\mathrm{O}$ & $\mathrm{O}$ \\
\hline & 정보 & 데이터 신뢰성 & & $\mathrm{O}$ & $\mathrm{O}$ \\
\hline & \multirow{5}{*}{ 시스템 } & 표준 준수성 & $\mathrm{O}$ & & $\mathrm{O}$ \\
\hline & & 접근 편의성 & & $\mathrm{O}$ & $\mathrm{O}$ \\
\hline & & 시스템 중복성 & & & $\mathrm{O}$ \\
\hline & & 시스템 확장 편의성 & & $\mathrm{O}$ & $\mathrm{O}$ \\
\hline & & 시스템 수정 편의성 & & & $\mathrm{O}$ \\
\hline & \multirow{2}{*}{ 비용 } & 투자 적합성 & & $\mathrm{O}$ & $\mathrm{O}$ \\
\hline & & 총비용 & & $\mathrm{O}$ & $\mathrm{O}$ \\
\hline
\end{tabular}

$\mathrm{PRM}$ 의 평가 지표가 제안 모델보다 부족하기 때문에 발생 한 것이다.

각 기관에 적용한 결과를 기반으로 본 연구에서 제안한 모델의 평가 지표가 추가적으로 필요한 이유는 다음과 같 다. 첫째, $\mathrm{PRM}$ 을 적용할 경우, 지표가 부족하기 때문에 중 요 개선 지표 $(<$ 표 10> 중 Bold 체)를 식별하지 못한다. 핵 심적인 문제를 식별하기 위해선 평가 기관의 목표 및 시사
〈표 10〉PRM 및 제안 모델의 적용 결과

\begin{tabular}{|c|c|c|c|}
\hline \multicolumn{2}{|r|}{ 구분 } & PRM & 제안 모델 \\
\hline & 평점 & 2.9 & 2.7 \\
\hline $\begin{array}{l}\mathrm{B} \\
\text { 기 } \\
\text { 관 }\end{array}$ & 개선지표 ${ }^{* *}$ & $\begin{array}{l}\text { 서비스 정확도 }(2)^{*} \\
\text { 서비스 응답시간(2) } \\
\text { 업무 활용성(2) } \\
\text { 접근 편의성(1) }\end{array}$ & $\begin{array}{l}\text { 서비스 정확도(2) } \\
\text { 서비스 응답시간(2) } \\
\text { 업무 활용성(2) } \\
\text { 접근 편의성 }(1)^{* * *} \\
\text { 자원 활용성(2) } \\
\text { 고객 편의성(2) } \\
\text { 지속적 측정(2) } \\
\text { 교육훈련주기(2) } \\
\text { 규정고려정도(1) }\end{array}$ \\
\hline & 평점 & 3.4 & 3.2 \\
\hline $\begin{array}{l}\mathrm{C} \\
\text { 기 } \\
\text { 관 }\end{array}$ & 개선지표 & $\begin{array}{l}\text { 업무 활용성(3) } \\
\text { 자원 공유성(3) } \\
\text { 예산낭비 절감율(3) } \\
\text { 사용자 요구사항(3) }\end{array}$ & $\begin{array}{l}\text { 업무 왈용성(3) } \\
\text { 자원 공유성(3) } \\
\text { 예산낭비 절감율(3) } \\
\text { 사용자 요구사항(3) } \\
\text { 업무 통보성(3) } \\
\text { 자원 활용성(3) } \\
\text { 자원 중복성(3) } \\
\text { 규정고려 정도(3) } \\
\text { 교육훈련주기(3) } \\
\text { 표준 준수성(3) } \\
\text { 참여도(2) } \\
\text { 평가방법구비성(2) } \\
\text { 지속적 평가 (2) }\end{array}$ \\
\hline & 평점 & 2.9 & 2.9 \\
\hline $\begin{array}{l}\mathrm{D} \\
\text { 기 } \\
\text { 관 }\end{array}$ & 개선지표 & $\begin{array}{l}\text { 서비스 정확도(2) } \\
\text { 예산낭비 절감율(2) } \\
\text { 데이터 신뢰성(2) }\end{array}$ & $\begin{array}{l}\text { 서비스 정확도 }(2) \\
\text { 예산낭비 절감율(2) } \\
\text { 데이터 신뢰성 }(2) \\
\text { 자원 중복성 }(2) \\
\text { 의사결정 신속성 (1) }\end{array}$ \\
\hline
\end{tabular}

* ( )는 평가 점수임.

** 평균보다 낮게 평가된 지표를 선정.

*** Bold 체로 표현한 것은 점수가 가장 낮은 개선 지표이며, 우선 적으로 다루어야할 개선지표임.

점과 성숙도를 고려한 성과지표가 필요하다. 두 번째로는 $\mathrm{PRM}$ 은 평가 모델로써 현재의 상태를 평가하는데 주력하고 있다면, 본 연구 모델은 성과평가뿐만 아니라 향후 성과를 향상시키기 위한 환경 평가(e.g. 지속적 평가, 평가방법구비 성 등)와 같은 향후 성과 향상을 고려한 지표가 포함되어있 다. 평가의 목적과 이유를 고려한다면 본 연구와 같은 평가 지표가 필요하다.

\section{5. 결 론}

공공부문 $\mathrm{EA}$ 는 지난 2006년부터 본격 도입되어 추진되고 있으나 기관에 따라 활용 및 운영 수준에 있어서 큰 차이가 있으며 각 기관별 $\mathrm{EA}$ 의 성과평가에 있어서도 성숙도 측정 이외에는 이렇다 할 특별한 방법이 없다.

따라서 본 연구에서는 이러한 문제를 해결하기 위해 기존 의 범정부 및 미 연방 성과참조모델과 $\mathrm{OMB}$ 및 범정부 $\mathrm{EA}$ 
성숙도 모델을 분석하여 성과 평가를 위한 업무성과, 고객 성과, 프로세스, 인적자본, 기술의 5 개 평가영역과 13 개 평가 항목, 30 개의 평가지표로 구성된 $\mathrm{EA}$ 성과평가 모델을 제안 하였다.

이렇게 제안한 모델을 검증하기 위해서 3 개 기관에 기존 의 $\mathrm{EA}$ 평가 모델과 제안한 평가모델을 적용하여 비교 분석 을 하였으며 이를 통해 적용성 및 유용성도 검증하였다. 그 리고 제안한 모델의 평가 결과에 따른 개선 지침과 지속적 인 성과향상 지침의 활용 방법도 함께 제시하였다. 또한, 제 안한 $\mathrm{EA}$ 성과평가모델과 기존의 $\mathrm{EA}$ 성숙도 모델, $\mathrm{PRM}$, 정 보화 성과평가 모델의 비교를 통해 특 - 장점도 살펴보았다.

그러나 실제 성과평가를 진행하는 과정에서 본 연구의 세 가지 한계점이 도출되었다. 첫째, 일반성이 결여 되었다. 이 는 기관내의 모든 조직을 대상으로 하였어야 했으나 시간적 및 조사환경의 한계성으로 인해 일부 부서만을 대상으로 조 사했기 때문에 이러한 문제점이 발생하였다. 두 번째 한계 점은 분석의 수준(Level of Analysis)이 높지 않다는 것이 다. 각 조직의 $\mathrm{EA}$ 구성 목적이 다르기 때문에 $\mathrm{EA}$ 의 성과를 바라보는 시각도 다를 것이다. 그러나 본 연구의 경우 $\mathrm{EA}$ 의 특징 및 $\mathrm{EA}$ 도입을 통해 얻을 수 있는 장점과 $\mathrm{EA}$ 성숙도 모델, $\mathrm{PRM}$ 을 기준으로 도출하였기 때문에 이러한 시각을 반영하지 못하는 한계점이 존재한다. 마지막 한계점으로는 각 평가요소의 도출 절차를 제시하지 않았다. 그러나 본 연 구가 $\mathrm{EA}$ 의 성과평가를 위한 성과평가 모델을 제시함으로써 다른 조직에서도 본 연구의 내용을 조정하여 충분히 활용될 것으로 기대된다.

향후 연구과제로는 보다 정확하고 객관적인 성과 평가를 위해 성과평가 지표 및 성과평가 요소를 도출하기 위한 평 가 프로세스 및 메트릭에 대한 연구를 수행하여야 할 것이다.

\section{참 고 문 헌}

[1] John A. Zachman, "A Framework for Information Systems Architecture", IBM Systems Journal, Vol.26, No.3, 1987.

[2] 이헌중, "ITA 개념", 한국 전산원 ITA 정기 세미나, 2006.

[3] Andrew Josey, "TOGAF Version 9, Enterprise Edition”, www.opengroup.org, 2009.

[4] The Chief Information Officers Council, "Federal Enterprise Architecture Frame- work Version 1.1”, 1999.

[5] Office of Management and Budget, EA Assessment Framework, http://www.whitehouse.gov/omb/egov/documents/ OMB_EA_Assessment_Framework_2_FINAL.pdf, 2005.

[6] 행정자치부, 전자정부아키텍처 도입을 위한 실무 가이드, 2005.

[7] 정보통신부, 정보기술아키텍처 도입/운영 지침, 2006.

[8] 정보통신부, “범정부 PRM 1.0”, 2005.

[9] W.H.Delone, E.R.Mclean, "The DeLone and McLean Model of Information System Success : A Ten-Year Update", Journal of Management Information System, Vol.19, No.4, pp.9-30,
2003.

[10] Kaplan R.S., Norton D.P, The balanced scorecard: measures that drive perfor mance, Harvard Business Review, pp.71-80, 1992

[11] Porter M.E, What is Strategy?, Harvard Business Review, pp.61-78, 1996.

[12] 유은숙, “전자정부의 효율성 측정을 위한 정보화 성과 평가 모 델”, 숭실대학교 박사학위 논문, 2004.

[13] 노재범, 이팔훈, 이승현, “서비스 이노베이션엔진 6시그마", 삼 성경제연구소, 2005 .

[14] Joseph A. De Feo, William Barnard, "Six Sigma Breakthrough and Beyond - Quality Performance Breakthrough Methods", McGraw-Hill, 2005.

[15] Fred D. Davis, Perceived Usefulness, Perceived Ease of Use, and User Acceptance of Information Technology, MIS Quarterly, pp.319-341, 1989.

[16] "Enterprise Architecture", "http://en.wikipedia.org/wiki/ Enterprise_Architecture", Wikipedia, 2008.

[17] Icek Ajzen, The Theory of Planned Behavior, Organizational Behavior and Human Decision Processes, pp.179-211, 1991.

[18] Peter Weill, MIT Center for Information Systems Research, Sixth e-Business Conference, 2007.

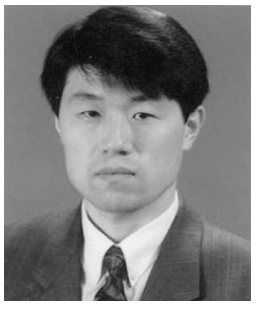

\section{이 석 균}

e-mail :dollee2@hanmail.net 1988년 명지대학교 전자계산학과(학사) 1998년 성균관대학교 행정대학원(석사) 2007년 숭실대학교 컴퓨터학과 박사과정 수료

1988년 1991년 의료보험연합회 전산부

1991년 2008년 경제기획원, 재정경제원, 기획예산처

2008년 현 재 기획재정부 근무

관심분야: 데이타베이스, 소프트웨어공학, $\mathrm{EA} / \mathrm{ITA}, \mathrm{BPM}$, 유비 쿼터스 컴퓨팅

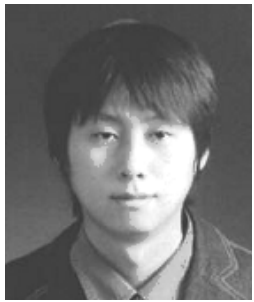

\section{이 영 민}

e-mail : leerin99@ssu.ac.kr 2005년 단국대학교 컴퓨터과학과(학사) 2007년 숭실대학교 컴퓨터학과(석사) 2007년 현 재 숭실대학교 컴퓨터학과 박사과정

관심분야: $\mathrm{SW}$ 개발방법론, 요구공학, $\mathrm{SW}$ 재공학/역공학, 오픈소스 


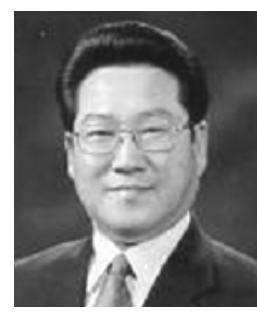

\section{류 성 열}

e-mail:syrhew@ssu.ac.kr

1977년 숭실대학교 전자계산학과(학사)

1980년 연세대학교 전자계산학과(석사)

1996년 아주대학교 컴퓨터공학과(박사)

1981년 현 재 숭실대학교 교수

1982년 1995년 숭실대학교 전자계산연구소

및 중앙전자계산소 소장

1997년 1998년 George Mason University 객원 교수

1998년 2001년 숭실대학교 정보과학대학원 원장

2004년 현 재 한국품질재단 운영위원회 위원장

2008년 현 재 정보통신연구진흥원 이사

관심분야: $\mathrm{SW}$ 공학, $\mathrm{SW}$ 요구공학, $\mathrm{SW}$ 유지보수, $\mathrm{SW}$ 재공학/역 공학, 오픈소스 